\title{
The Five Temptations of a CEO
}

\author{
By Patrick M. Lencioni
}

San Francisco, CA: Jossey-Bass, Publishers, 1998, 134 pages

\section{Reviewed by Dr. Robin L. Love}

Assistant Professor, Department of Child Development

San Jose State University

The Five Temptations of a CEO is a fascinating readable look at the issues involved in successful leadership. The book's story-like format is simple to understand, yet highlights the basic principles inherent in the challenging job of management. The author, Patrick Lencioni is president of a consulting firm, which specializes in organizational development, and consequently, he brings to his writing considerable expertise working with and coaching business executives.

The first impression of readers in higher education might be to wonder what, if anything, a book about corporate management would have to say about college programs. However, Lencioni's principles of management transcend the corporate world. His advice can be equally applicable for educational leaders (whether administrators or teachers), as it is for business executives.

The book is composed of four parts: an introduction, a fable, explanation of the model, and a self-assessment tool for readers. In the introduction, Lencioni presents the premise of this book, that while a chief executive's job may be challenging, even difficult, the underling principles are quite simple. He went so far as to write that, "... a CEO's success hinges on just a few behaviors..." (p. viii). When executives fail, they do so because they are making basic and identifiable mistakes. Many executives prefer to focus on the details of their jobs, rather than engage in the more troubling selfexamination of their leadership capability. Lencioni's book cuts past the less relevant details to the heart of leadership.

Lencioni first explains his principles through "The Fable," which is the story of Andrew, the CEO of Trinity Systems, a fictitious high-tech firm located in San Francisco. Andrew is facing the end of his first year as his company's CEO, and the first board meeting at which he will be held responsible for the gains and loss of the fiscal year. He considers his company's year as "unspectacular at best" (p. 5), but is only marginally concerned as he feels that the company's performance can be attributed to a number of causes (e.g., the product market, loss of a key executive, etc.). Through a series of happenstance, Andrew finds himself headed home on a Bay Area Rapid Transit train (BART) at midnight before this crucial board meeting. The only other occupant of that BART car is an elderly man, named Charlie, who appears to Andrew to be the janitor. Andrew tries to politely ignore Charlie, but is forced to follow him into another train car and converse, after there is an apparent stall along the BART line. Charlie explains to Andrew the five "temptations" to which CEOs are vulnerable.

Lencioni is an engaging storyteller, and "The Fable" is a clever way to communicate the ideas in his model. Readers can sense Andrew's frustration, his patronizing attitude, and ultimately share his growing interest in the ideas that Charlie presents. As Andrew 
becomes intrigued, Charlie takes him into another BART car to continue their discussion with three other men who all appear to be CEOs. Together, the men take Andrew through a spirited discussion of the five temptations. Andrew wakes to find that the whole experience was a dream as the BART train pulls into his station. However, when Andrew attends the Trinity Systems' board meeting the following morning, it is clear that he has come to understand the personal responsibility that a leader must take in the form of the basic principles implied in the five temptations. Andrew compares his late night experience on the BART to stepping into an episode from the "Twilight Zone." While the his dream certainly has a strange, eerie quality, once Andrew finds out the identities of his four companions on the train - the episode seems more reminiscent of Kevin Costner's "Field of Dreams" ("Build a field [...or take public transportation...], and they will come").

The next portion of the book describes Lencioni's model for successful leadership. He described the five temptations, as well as the management principle inherent in each. The five principles were:

1) Focus on results rather than personal status. Lencioni wrote, "great CEOs should be almost overwhelmed by the need to achieve something. That is what drives them. Achievement. Not ego" (p. 30). When leaders focuses on personal success, they concentrate on protecting their status. This motive causes them to lose their "edge," their willing to take risks, and they fail to recognize workers who could contribute to the organization (but who may not acquiesce to the boss).

2) Hold "direct reports" (e.g., managers working under you) accountable for meeting their commitments. Many leaders succumb to the temptation to feel popular among their immediate subordinates. Consequently, they fail to let their workers know what is expected of them.

3) Have clear goals. Lencioni stressed the need for willingness to achieve clarity, even when you are not certain of all the facts. An organization is paralyzed by indecision. Subordinates need a clear sense of what is required of them, and some action is better than no action at all. If, when all the facts are available, you were mistaken, then admit the mistake and move on.

4) Tolerate discord. Encouraging co-workers to share their views and disagree is the means to "productive ideological conflict" (p. 116). Letting subordinates disagree with each other and with you allows a leader to gather many perspectives on an issue (and hence make better informed decisions). Promoting harmonious interactions can often stifle conflicting (but valuable) input.

5) Engender a sense of trust in your workplace. Be willing to be trusting and vulnerable with your subordinates, value their contributions. Giving your workers that power allows them to be trusting with each other, and with you. Trust leads to a greater sense of honesty and willingness to share ideas.

The last chapter of the book is "Self-Assessment." In this section, Lencioni provides readers with questions that will allow them to reflect on their own potential weaknesses in leadership. Along with this diagnostic tool, the author provides an 
additional rationale that explains the problems inherent in succumbing to each of the temptations.

The Five Temptations of a CEO, while designed to explain the success of corporate management styles, describes a flexible model that can be as easily adapted to those in management positions in college and university communities. The need for accurate assessment is a growing concern on many campuses, and one that occurs at any number of levels: student outcomes, teacher effectiveness, and program or departmental viability. As colleges search for effective measurement tools or standards by which to gauge successes or target areas for improvement there seems to be little discussion of leadership quality. Although many in higher education seem to know when there is an effective leader, few seem to be able to clearly articulate the qualities that make one leader successful, and another less effective. The model that Lencioni described in this book (i.e., focus on results, accountability, clarity, tolerance of discord, and engendering trust) appears to be as beneficial to a successful college administrator or teacher, as to a Fortune 500 CEO. Reading The Five Temptations of a CEO can provide college and university leaders the opportunity to consider their own management styles and how they might more effectively inspire and direct those with whom they work. 